\title{
PERAN RELIGIUSITAS ISLAMI DAN KESEJAHTERAAN SUBYEKTIF TERHADAP PEMAAFAN REMAJA SISWA MADRASAH ALIYAH NEGERI III YOGYAKARTA
}

\author{
THE ROLE OF ISLAMIC RELIGIOSITY AND SUBJECTIVE WELFARE TO \\ FORGIVENESS OF TEENS STUDENTS MADRASAH ALIYAH \\ NEGERI III YOGYAKARTA
}

\author{
Ahmad Muhammad Diponegoro \\ Sutipyo Ru'iya \\ Universitas Ahmad Dahlan
}

\begin{abstract}
Abstrak
Penelitian ini dikembangkan berdasarkan fenomena remaja akhir-akhir ini yang semakin banyak mengalami permasalahan dalam kehidupan sosialnya, seperti tawuran, geng, dan kegelisahan yang menyebabkan mereka mengalami gangguan ketika di sekolah. Fenomena ini mengindikasikan tingkat subjective weel being yang kurang terpenuhi. Salah satu faktor pencapaian subjective weel being adalah religiusitas dan pemaafan. Oleh karena itu, penelitian ini bertujuan untuk menganalisis hubungan religiusitas dan pemaafan dengan subjective weel being (SWB) remaja siswa Madrasah Aliyah Negeri III Yogyakarta. Penelitian ini menggunakan pendekatan kuantitatif dengan subyek penelitian adalah kelas XI siswa Madrasah Aliyah Negeri III Yogyakarta. Hasil penelitian menunjukkan Tidak ada pengaruh langsung religiusitas terhadap pemaafan. Ada pengaruh tidak langsung religiusitas terhadap pemaafan sebesar 0,129. Ada pengaruh langsung religiusitas terhadap kepuasan hidup sebesar 0,172 $(p=0,053)$ dan pengaruh tidak langsung sebesar 0,124, total pengaruh 0,296. Ada pengaruh langsung religiusitas terhadap afek sebesar 0,294 ( $p=0,002)$. Hasil penelitian ini juga menunjukkan ada pengaruh langsung afek terhadap kepuasan hidup sebesar 0,419 dan ada pengaruh langsung afek terhadap pemaafan sebesar 0,204 $(p=0,048)$ dan pengaruh tidak langsung sebesar 0,301 sehingga total pengaruh sebesar 0,301; serta ada pengaruh langsung kepuasan hidup terhadap pemaafan sebesar 0,232 $(p=0,024)$. Berdasarkan hasil penelitian dapat disimpulkan bahwa untuk meningkatkan pemaafan pada remaja, maka perlu ditingkatkan religiusitas dan peningkatan kesejahteraan subyektifnya (subjective weel being).
\end{abstract}

Kata kunci: subjective well being, pemaafan, religiusitas

\section{Abstract}

This study was developed based on the phenomenon of late adolescents are increasingly experiencing problems in their social life, such as fights, gangs, and the anxiety that causes them to crash when in school. This phenomenon indicates the level of subjective less weel being met. One achievement of subjective factors weel being is religiosity and forgiveness. Therefore, this study aimed to analyze the relationship between religiosity and forgiveness with Subjective weel-being (SWB) adolescent students of Madrasah Aliyah III Yogyakarta. This study uses a quantitative approach to research subject is class XI student of Madrasah Aliyah III Yogyakarta. The results showed There is no direct effect of religiosity on forgiveness. There is the indirect effect of religiosity on the forgiveness of 0.129. There is a direct influence of religiosity on the life satisfaction of $0.172(p=0.053)$ and the indirect effect of 0.124, the total effect of 0,296. There is a direct influence of religiosity on the affect of $0.294(p=0.002)$. The results also indicate there is 
a direct influence of affect on the life satisfaction of 0.419 and there is a direct influence of affect on the forgiveness of $0.204(p=0.048)$ and the indirect influence of 0.301 so that the total effect of 0.301; and there is a direct influence on the life satisfaction of forgiveness of $0.232(p=0.024)$. Based on the results of this study concluded that in order to increase forgiveness in adolescents, it is necessary to be increased religiosity and increase their subjective well-being (subjective weel-being).

Keywords: subjective well being, forgiveness, religiosity

\section{PENDAHULUAN}

Kebahagiaan yang menjadi dambaan setiap orang, tentu juga didambakan oleh remaja yang merupakan tahap tertentu dalam perkembangan manusia. Dalam kajian psikologi perkembangan, remaja merupakan tahap perkembangan setelah masa anak dan sebelum masa dewasa. Artinya, remaja berada pada posisi peralihan antara masa anak ke masa dewasa. Masa remaja yang mengalami banyak perubahan, baik secara fisik, mental, hingga perubahan dalam penyesuaian sosial, menurut Gunarsa (Okvianti, 2011) rentan menimbulkan masalah yang mengakibatkan hilangnya keseimbangan psikis seperti terlihat dengan munculnya kegelisahan, kebingungan dan timbulnya masalah emosi.

Reaksi setiap remaja dalam menghadapi gejolak emosi juga sangat beragam, hal ini selain dipengaruhi latar belakang perkembangan masa sebelumnya, lingkungan juga dapat menjadi salah satu penyumbang dalam mengatasi ledakan emosi serta berbagai permasalahan yang dialami individu. Masa remaja yang identik dengan berkembangnya lingkungan sosial tempat beraktivitas, membuat mereka dituntut untuk dapat menyesuaikan diri secara efektif (Hurlock, 1997). Oleh karena itu, sebagian besar remaja mengalami ketidakstabilan emosi dari waktu ke waktu sebagai konsekuensi dari usaha penyesuaian diri pada pola perilaku baru dan harapan sosial yang baru. Arnett (Diponegoro, 2010) mengatakan bahwa persoalan yang diaalami remaja menambah tingginya stressor negatif seperti konflik diantara teman sebaya, ketergantungan terhadap orangtua, kebingungan dalam menentukan karir maupun pendidikan. Keadaan ini dapat menyumbang terhadap penurunan substansial kualitas kehidupan remaja yang merupakan indikator kebahagiaan. Indikasi lain dari ketidakbahagiaan remaja masa kini antara lain banyaknya remaja yang sering melakukan perkelahian terutama perkelahian antar geng. Terlihat dari tahun ke tahun jumlah perkelahian dan korban cenderung meningkat. Bahkan sering tercatat dalam satu hari terdapat sampai tiga perkelahian di tiga tempat sekaligus (http://erizta.student.umm.ac.id).

Kenyataan remaja tersebut di atas sangat memperihantinkan, padahal remaja merupakan penerus sebuah bangsa. Bagaimana jadinya jika sebagian besar remaja saat ini tidak bahagia? Padahal kebahagiaan merupakan hal yang sangat penting, sebab dengan bermodal kebahagiaan seseorang akan lebih mudah berbuat baik. Myers (Anam, 2007) menyatakan: happy people are helpful people. Hanya orang yang merasa bahagia akan mudah melakukan pertolongan pada orang lain. Individu yang merasa bahagia akan senang dengan teman dekat dan keluarga. Individu tersebut juga kreatif, optimis, kerja keras, tidak mudah putus asa, dan tersenyum lebih banyak daripada individu yang menyebut dirinya tidak bahagia (Myers, 1999). Individu yang bahagia lebih cenderung untuk tidak memikirkan diri sendiri, kurang rasa bermusuhan, akrab dengan individu lain, sedikit melakukan agresi, dan lebih tahan menghadapi penyakit dibandingkan individu yang tidak bahagia dan lebih suka menolong (Salovey et al., 2000).

Kata kebahagiaan, menurut Diener (Diponegoro, 2010) istilah ilmiahnya adalah kesejahteraan subjektif (Subjective well being). Oleh karena itu, untuk menyatakan istilah kebahagiaan pada pada penelitian ini selanjutnya akan digunakan istilah kesejahteraan subjektif (Subjective well being) agar lebih terlihat nilai ilmiahnya.

Berdasarkan pada berbagai hasil penelitian yang dilakukan Yamamoto (2006), subjective well being memiliki keterkaitan erat dengan 
beberapa dimensi seperti pemenuhan kebutuhan dan keinginan, sumber daya, kepuasan hidup, nilai-nilai, dan kepribadian. Lebih lanjut, Yamamoto (2006) menarik kesimpulan terkait dengan definisi subjective well being sebagai proses pemenuhan kepuasan atas kebutuhan universal dengan mengacu pada faktor personal, kultural dan kondisi kontekstual.

Secara khusus Breadshaw dkk (2009) mengatakan bahwa kesejahteraan subyektif remaja dapat dipengaruhi oleh banyak hal, diantaranya adalah: gender, usia, tipe keluarga, etnis, afiliasi keberagamaan, disability, kesulitan belajar, dan status ekonomi. Penelitian yang dilakukan Diponegoro (2004) menghasilkan bahwa nilai ajaran Islam berperan pada kepuasan hidup dan afek (kesejahteraan subjektif) remaja Islam. Ini berarti semakin tinggi nilai ajaran Islam, maka semakin tinggi kepuasan hidup dan afek remaja Islam.

Al qur'an dan hadist merupakan pedoman umat muslim di dunia, untuk mencapai kebahagiaan dunia dan akhirat. Dalam Al-Qur'an dan Hadist banyak ditemukan nilai-nilai yang penting bagi kehidupan (Diponegoro, 2012). Salah satu nilai tersebut berkaitan dengan kesejahteraan subjektif. Faktor-faktor yang berperan pada kesejahteraan subyektif remaja Islam adalah faktor taqwa kepada Allah, hubungan sesama manusia, hubungan dengan kerabat, lingkungan, dan diri sendiri. Trede (2006) mengatakan Subjective well being mempunyai korelasi dengan religiusitas dan tidak ada keterkaitan yang signifikan dengan simtomatologi depresif masa depan.

Mengingat salah satu faktor yang berperan pada kesejahteraan subyektif remaja adalah hubungan (relasi) seseorang (remaja) baik dengan Tuhan, orang sekitar dan keadaan sekitar, maka ada satu hal yang tidak kalah pentingnya untuk diperhatikan yaitu hubungan antara kebahagiaan dengan pemaafan. Lebihlebih apabila memperhatikan tugas-tugas perkembangan remaja menurut Havighurst (Willis, 2005) yang antara lain: 1) memperoleh sejumlah norma-norma dan nilai-nilai, 2) belajar memiliki peranan sosial sesuai dengan jenis kelamin masing-masing, 3) menerima kenyataan jasmaniah serta dapat menggunakannya secara efektif dan merasa puas terhadap keadaan tersebut, 4) mencapai kebebasan dari kebergantungan terhadap orangtua dan orang dewasa lainnya, 5) mencapai kebebasan ekonomi, 6) mempersiapkan diri untuk menentukan suatu pekerjaan yang sesuai dengan bakat dan kesanggupannya, 7) memperoleh informasi tentang perkawinan dan mempersiapkannya, 8) mengembangkan kecakapan intelektual dan konsep-konsep tentang kehidupan bermasyarakat, serta 9) memiliki konsepkonsep tingkah laku sosial yang perlu untuk kehidupan bermasyarakat.

Kompleksitas perubahan pada diri remaja membawa suatu sifat yang sangat mencolok pada remaja yaitu sifat egosentrisme. Menurut psikolog perkembangan Elkin (Santrock, 2004), sifat egosentrisme remaja terdiri dari dua macam yaitu imaginary audience dan personal fable. Kedua jenis egosentrisme ini menggambarkan keunikan masa remaja dimana remaja menginginkan dirinya menjadi pusat perhatian dan menginginkan setiap orang bersikap pada dirinya seperti apa yang dia inginkan. Dengan sifat egosentrisme ini sangatlah mungkin terjadi ketidakpuasan pada remaja menyangkut relasi sosialnya. Ketidakpuasan bahkan perasaan tersakiti pada remaja karena tidak dapat memperoleh seperti apa yang diinginkan oleh sifat egosentrismenya itu akan menjadi faktor penghalang kesejahteraan subyektifnya, kecuali orang tersebut dapat memaafkannya

\section{KAJIAN LITERATUR Konsep Dasar Subjective Well Being}

Menurut Diener (2008) subjective well being sebagai konsep psikologis dalam kehidupan individu yang mengandung beberapa dimensi antara lain: kepuasan hidup yang meliputi kepuasan terhadap hal-hal penting dalam kehidupan, perasaan positif yang tinggi, dan perasaan negatif yang rendah. Definisi yang mirip juga disampaikan oleh Headey dan Wooden (2004) yaitu subjective well being mengandung dimensi kepuasan hidup dan perasaan yang positif seperti vitalitas dan perasaan nyaman. Headey \& Wooden (2004) juga menambahkan bahwa subjective well being lebih ditentukan oleh sifat kepribadian, seperti hubungan personal, dan partisipasi individu dalam kehidupan sosial.

Senada dengan Bradshaw dkk (2009) yang mendefinisikan subjective well being sebagai konsep multidimensional yang mengandung komponen kognitif dan 
komponen afektif. Hal ini meliputi pengalaman perasaan positif atau emosi yang menyenangkan, perasaan negatif, dan penilaian individu atas kualitas kehidupan yang dijalaninya.

Berdasarkan beberapa definisi tersebut, maka peneliti menyimpulkan bahwa kesejahteraan subyektif (subjective well being) yaitu hasil evaluasi kognitif seorang individu yang mengandung dimensi kepuasan hidup dan afek (perasaan) positif dan negatif tentang kehidupan yang dialaminya.

Mengingat begitu luasnya variabel kesejahteraan subyektif, menurut Muhadjir (2011) perlu dilakukan pengembangan variabelitas agar hasil suatu penelitian lebih "sempurna”. Berdasar pendapat tersebut, maka variabel kesejahteraan subyektif dalam penelitian ini dikembangkan menjadi variabel kepuasan hidup dan afek.

\section{Pengertian Afek dan Kepuasan Hidup}

Afek dalam penelitian ini diartikan sebagai suasana hati yang dialami individu dalam menikmati pengalaman-pengalamannya di masa lalu dan sekarang. Jika individu memiliki afek positif maka dia akan bersemangat, aktif, yang ditandai dengan energi yang tinggi, penuh konsentrasi, dan penuh kenyamanan. Sedangkan jika memiliki afek negatif, individu tersebut akan merasakan ketegangan dan ketidak nyamanan sebagai akibat dari berbagai mood yang tidak mengenakkan seperti marah dan lain sebagainya.

Sedangkan kepuasan hidup diartikan sebagai evaluasi kognitif individu dalam menikmati pengalaman-pengalamannya di masa lalu dan sekarang. Individu yang puas memiliki penilaian bahwa apa yang sudah dicapai atau diperolehnya sudah sesuai dengan harapan atau cita-citanya dan memandang secara positif kehidupannya di masa yang akan datang.

\section{Religiusitas Islami mempengaruhi Kesejahteraan Subyektif}

Berdasarkan hasil penelitian

Diponegoro (2004) dan Trede (2006) kesejahteraan subyektif dipengaruhi oleh banyak hal, diantaranya adalah unsur kepercayaan seseorang kepada Tuhan. Beberapa ajaran agama berpotensi untuk meningkatkan kesejahteraan subyektif adalah kepercayaan akan adanya hidup sesudah mati, adanya surga dan takdir (segala sesuatu yang telah ditentukan terhadap seseorang mempunyai arti yang positif bagi individu tersebut) (Diener et al., 1999).

Nilai-nilai ajaran agama yang terkandung dalam berbagai kitab suci menurut Seligman (1999) juga berpotensi untuk meningkatkan kesejahteraan subyektif, karena mengandung nilai hidup yang positif. Benson (Diponegoro 2004) seseorang yang secara mendalam berdoa yang diulang-ulang (repetitive prayer) akan terjadi proses respon relaksasi dalam diri individu. Hal inilah yang menurut ajaran Islam yang disebut dengan religiusitas islami. Dimana religiusitas islami didefinisikan sebagai seberapa kuat keimanan, kepercayaan-kepercayaan (akidah) seorang muslim yang maka ajaran agama yang dianutnya dipraktekkan oleh dalam kehidupannya sehari-hari sebagai pribadi muslim yang kaffah.

Pengertian religiusitas islami diatas mengantarkan pada aspek-aspek religiusitas, yang menurut Glock \& Stark (Nashori dan Mucharam, 2002) ada lima yang meliputi, ideological, ritualistic, consequential, experiential, dan intellectual. Menurut Kraus (2005) Glock \& Stark dalam menentukan aspek religiusitas berpijak pada agama Nasrani.

Penelitian ini mengkhususkan pada religiusitas islami, yang mempunyai kekhususan dalam beberapa hal diantaranya adalah pandangan dalam tauhid. Untuk itulah religiusitas islami pada penelitian ini berpijak kepada aspek yang dikemukakan oleh Kraus (2005) yang disusun benar-benar dari ajaran Islam. Aspek tersebut meliputi: a) Islamic worldview (pandangan terhadap agama Islam yang lebih dikenal dengan akidah dan tauhid) yang terdiri sub-aspek; creator and creation, existence and transcendence, dan all encompassing religion; dan b) religious personality (kepribadian agamis) yang terdiri sub-aspek; Self (self-directed), Social (interpersonal - interactive) dan Ritual (formal worship). Dengan berdasar pada aspek-aspek tersebut peneliti berharap dapat mengungkap religiusitas responden yang sebenarnya.

\section{Pemaafan mempengaruhi Kesejahteraan Subyektif \\ Variabel lain yang diduga} mempengaruhi kesejahteraan subyektif pada penelitian ini yang diteliti juga adalah pemaafan. Pemaafan diduga mempunyai 
peranan besar yang tidak kalah pentingnya untuk di perhitungkan dalam menentukan kesejahteraan subyektif remaja sebagaimana yang dinyatakan oleh Elkin (Santrock, 2004) jika dihubungkan dengan sifat remaja yang egosentrisme. Sifat egosentrisme remaja sangat berpengaruh dalam kehidupannya, dimana seorang remaja harus banyak berhubungan sosial dengan orang lain. Seorang remaja yang terlalu egosentrisme itu akan mengalami kesulitan dalam pergaulan kehidupannya sehari-hari. Oleh karena itulah, seorang remaja dituntut untuk mempunyai sifat memaafkan yang besar.

Menurut Enright (2002) pemaafan adalah kesediaan seseorang untuk meninggalkan kemarahan, penilaian negatif, dan perilaku acuh-tidak-acuh terhadap orang lain yang telah menyakitinya secara tidak adil. McCullough dkk (1997) mengartikan pemaafan sebagai seperangkat motivasi untuk mengubah sikap seseorang agar tidak membalas dendam dan meredakan dorongan untuk memelihara kebencian terhadap pihak yang menyakiti serta meningkatkan dorongan untuk konsiliasi hubungan dengan pihak yang menyakiti.

Wardhati dan Faturochman (2006) mendefinisikan pemaafan adalah upaya membuang semua keinginan pembalasan dendam dan sakit hati yang bersifat pribadi terhadap pihak yang bersalah atau orang yang menyakiti dan mempunyai keinginan untuk membina hubungan kembali.

Snyder dan Lopez (2007), menyatakan bahwa definisi yang diberikan Thompson dkk merupakan definisi yang paling inklusif di antara semua teori tentang pemaafan, sebab mereka berpendapat bahwa sumber pelanggaran maupun objek pemaafan dapat mengacu pada diri sendiri, orang lain atau sejumlah orang, atau situasi yang dinilai seseorang melebihi batas kemampuan pengendaliannya (seperti penyakit, "nasib", atau bencana alam).

\section{METODE PENELITIAN \\ Hubungan Antar Variabel}

Friedman dan Toussaint (2005) menduga bahwa ada hubungan positif antara pemaafan, bersyukur, distress dengan well being. Alasan yang memperkuat bahwa pemaafan dapat berhubungan dengan well being adalah karena pemaafan sangat berhubungan dengan ketentraman (kesejahteraan) rohani. Tokoh psikologi yang lebih terang-tengangan dalam hal ini adalah Tsang et al. (Diponegoro, 2010) yang membuktikan bahwa pemaafan yang berasal dari agama-agama besar dunia termasuk Islam, mampu meningkatkan kepuasan hidup dan afek positif individu sehingga mencegah konflik antar individu. Hal ini disebabkan karena para pemeluk agama memahami betul tentang sifat Tuhan yang Maha Pengampun, lalu pemahaman itu mereka aplikasikan dalam kehidupan sehari-hari berupa pemaafan terhadap sesama.

Penelitian serupa dilakukan lagi oleh Toussaint dan Friedman (2008) melakukan sebuah penelitian tentang hubungan antara pemaafan, bersyukur dan well being dari beberapa pasien rawat jalan psikoterapi. Dari 72 partisipan itu diketahui bahwa unsur pemaafan dan bersyukur diduga mempunyai peranan yang meyakinkan dalam peningkatan subjective well being pada seseorang. Seligman (2005) memberikan alasan mengapa pemaafan dapat meningkatkan subjective well being, yaitu karena dengan pemaafan memberikan kesan kenangan baik tentang masa lalu, sehingga akan menghilangkan kesan negatif yang menyesakkan dada.

Lebih lanjut, Winkellman (2006) juga menyatakan bahwa subjective well being dipengaruhi oleh kapasitas modal sosial. Hal ini mengacu pada sejauh mana kemampuan individu dalam menjalin relasi dan hubungan pada lingkungan sosial yang terkait kehidupannya.

Safren, Radomsky, Otto, dan Salomon (Diponegoro, 2010) menyatakan bahwa subjective well being bisa dilihat berdasarkan beberapa prediktor yaitu kepuasan individu terhadap dukungan sosial dan keyakinan yang anutnutnya. Menurut Myers (Diponegoro, 2010) mengatakan bahwa aspek religiusitas yang bersifat komunal berpengaruh positi terhadap kepuasan hidup dan afek yang nantinya akan membawa kepada kehidupan yang lebih baik baik pemeluk agama tersebut. McCullough (Diponegoro, 2010) juga menegaskan bahwa orang yang aktif menjalankan perintah agama akan mendapat kepuasan hidup sebagai prediktor kebahagiaan yang yang ditandai dengan mereka mempunyai umur yang lebih panjang.

Kondisi inilah yang menjadi dasar dalam penyusunan model penelitian ini, yakni 
bahwa subjective well being individu turut dibentuk oleh pemaafan (forgiveness) yang dikembangkannya keyakinan atau religiusitas seseorang seperti pada gambar berikut ini:

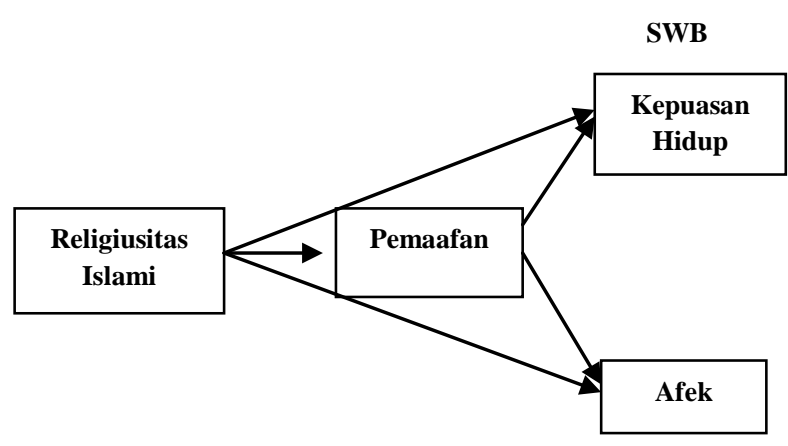

\section{Gambar 1. Gambar Awal}

\section{Populasi dan Sampel}

Populasi dalam penelitian ini adalah seluruh remaja siswa kelas $\mathrm{X}$ MAN Yogyakarta III. Berdasarkan data yang diperoleh dari pihak sekolah, populasi remaja siswa kelas XI MAN Yogyakarta III sebanyak 207 orang terdiri dari kelas XI IPA-1, 2, dan 3; kelas XI IPS-1, 2, 3, dan 4; serta kelas XI AGAMA.

Adapun penelitian ini menggunakan sampel yang dipilih dengan teknik cluster random sampling. Berdasarkan Nomogram Herry King dengan jumlah populasi di atas maka sampel yang diambil sebanyak kurang lebih 127 orang. Kelas yang terpilih sebagai sampel penelitian yaitu kelas XI IPA-1, IPA-2, dan IPS-1,2,3, dengan jumlah keseluruhan kurang lebih 130 orang.

\section{Alat Pengumpulan data}

Untuk mengungkap gejala psikologi dari empat variabel dalam penelitian ini digunakan skala yang diadaptasi dari beberapa skala sebelumnya yang telah terbukti keandalannya.

Kepuasan hidup diungkap dengan Satisfaction with Life Scale (SWLS) dengan mengacu pada aspek-aspek yang Gilman (2001) dengan jumlah item 23, kepuasan terhadap diri 5 item, keluarga 5 item, sekolah 4 item, kawan 3 item, lingkungan 6 item. Interval angket ini berkisar antara sangat sesuai dan sangat tidak sesuai, dengan skala penilaian 5 sampai 1 .

Alat ukur afek menggunakan Positive Affect \& Negative Affects Schedule (PANAS) yang dikembangkan dari skala Watson, Clark, dan Tellegen (1988) dengan cara adaptasi bahasa. Skala afek terdiri dari 18 item yang terdiri dari 9 afek positif dan 9 afek negatif. Alternatif jawaban pada skala ini yaitu selalu, sering, kadang-kadang, jarang dan tidak pernah. $\mathrm{C}_{i} \quad$ SWB enilaian untuk afek positi untuk jawaban selalu, nilai 4 untuk jawaban sering, nilai 3 untuk jawaban kadang-kadang, nilai 2 untuk jawaban jarang, dan nilai 1 untuk jawaban tidak pernah. Sedangkan penilaian untuk afek negatif adalah sebaliknya.

Skala HFS (The Heartland Forgiveness Scale) digunakan untuk mengungkap pemaafan yang diadaptasi dari Thompson et al (2005). Jumlah item skala ini adalah 17 yang terdiri dari 6 item pemaafan terhadap diri sendiri, 6 item pemaafan terhadap orang lain dan 5 item pemaafan terhadap situasi. Alternatif jawaban pada skala ini adalah sangat jarang, jarang, kadangkadang, sering, dan sangat sering. Penilaiannya adalah angka 1 untuk pilihan sangat jarang bergerak sampai 5 untuk pilihan sangat sering pada item-item favorabel dan penilaian sebaliknya untuk item-item unfavorable.

Sedangkan untuk mengukur Religiusitas islami, peneliti menggunakan skala Moslim Religiusity Personality Inventory (MRPI) yang disusun oleh Kraus (2005) dengan beberapa modifikasi. Skala MRPI ini terdiri dari dua skala yaitu 1) Islamic Worldview (pandangan terhadap Islam/tauhid atau akidah) dan 2) Religious Personality (kepribadian beragama). Jumlah item keseluruhan dari skala ini adalah 49 item yang terdiri dari 22 item skala Islamic Worldview yang terdiri dari 7 item aspek kepercayaan kepada Pencipta dan Ciptaan Allah, 7 item aspek kepercayaan kepada hal yang ghaib, hari akhirat, dan pembalasan amal, dan 8 item aspek kepercayaan bahwa ajaran Islam berlaku dan relevan untuk diterapkan dalam setiap waktu dan zaman. Alternatif jawaban dan penilaian untuk skala ini adalah: Nilai 1 untuk jawaban Tidak Sesuai Sama Sekali dengan Pandangan Saya, nilai 2 untuk jawaban Kurang Sesuai dengan Pandangan Saya, nilai 3 untuk jawaban Saya Ragu-ragu, nilai 4 untuk jawaban Mirip dengan Pandangan Saya, nilai 5 untuk jawaban Sama Persis dengan Pandangan Saya. Penilaian ini berlaku untuk item yang favorable dan berlaku sebaliknya untuk item unfavorable. 
Adapun skala Religious Personality terdiri dari 27 item, yang terdiri dari 8 item aspek hubungan dengan diri sendiri, 10 item aspek hubungan sosial dengan orang lain dan ciptaan, dan 9 item aspek hubungan dengan Tuhan (komitmen dalam ibadah mahdah). Alternatif pilihan jawaban dalam skala ini disediakan empat alternatif jawaban: Tidak pernah (TP), Jarang (JR), Kadang-kadang (KD), Sering (SR), Selalu (SL). Penilaian yang diberikan bergerak dari angka 5-1 untuk item yang favorable, dan penilaian bergerak dari 15 untuk item yang berbentuk unfavorable.

\section{Analisis Data}

Dalam menganalisis data dari hasil penelitian ini peneliti menggunakan teknik analisis model struktural jalur yang dikenal dengan Structural Equation Modelling (SEM) dengan menggunakan program AMOS 5.0. Dengan SEM dari program AMOS ini dapat melakukan estimasi terhadap beberapa persamaan regresi yang terpisah, namun saling berhubungan, dan secara simultan. AMOS ini berbeda dengan analisis regresi, sebab terdapat beberapa variabel terikat, dan variabel terikat ini bisa menjadi variabel bebas bagi variabel terikat yang lain. Pada prinsipnya AMOS ini menguji hubungan sebab akibat antar variabel seperti yang dikemukakan oleh peneliti pada bagian sebelumnya.

\section{HASIL PENELITIAN DAN PEMBAHASAN}

Secara umum ada karakteristik utama dalam analisis SEM, yaitu: estimasi beberapa hubungan yang saling terkait. Untuk keperluan ini harus diidentifikasi variabel terikat dan variabel bebasnya berdasarkan pengalaman atau teori. Dari tampilan komputasi AMOS juga dapat dilakukan interpretasi terhadap hasil-hasil perhitungan untuk menguji hipotesis yang diajukan. Namun sebelum melakukan interpretasi terhadap hasil-hasil perhitungan, AMOS mensyaratkan model harus fit terlebih dahulu. Dari hasil analisis goodness of fit pada model awal, ternyata model belum memenuhi kriteria goodness of fit, seperti pada tabel 1.

Tabel 1. Rangkuman Hasil Pengujian Gambar 1.

\begin{tabular}{|c|c|c|c|c|}
\hline No & $\begin{array}{c}\text { Goodness } \\
\text { of Fit }\end{array}$ & $\begin{array}{c}\text { Cut- } \\
\text { off }\end{array}$ & Hasil & Keterangan \\
\hline
\end{tabular}

\begin{tabular}{|l|l|l|l|c|}
\hline & \multicolumn{1}{|c|}{ Index } & value & & \\
\hline 1 & $\begin{array}{l}\text { Degree of } \\
\text { freedom }\end{array}$ & $>0,05$ & 1 & Baik \\
\hline 2 & $\begin{array}{l}\text { Probability } \\
\text { level }\end{array}$ & $>0,05$ & 0 & Tidak baik \\
\hline 3 & Chi Square & $>0,05$ & 15,772 & Baik \\
\hline 4 & $\begin{array}{l}\text { Goodness } \\
\text { of Fit } \\
\text { Index } \\
\text { (GFI) }\end{array}$ & $>0,900$ & 0,943 & Baik \\
\hline 5 & $\begin{array}{l}\text { Adjusted } \\
\text { GFI } \\
\text { (AGFI) }\end{array}$ & $>0,900$ & 0,343 & Tidak baik \\
\hline 6 & $\begin{array}{l}\text { Normal Fit } \\
\text { Index } \\
\text { (NFI) }\end{array}$ & $>>, 900$ & 0,722 & Tidak baik \\
\hline 7 & $\begin{array}{l}\text { Tucker- } \\
\text { Lewis } \\
\text { Index (TLI) }\end{array}$ & $\begin{array}{l}> \\
0,900\end{array}$ & $-7,756$ & Tidak baik \\
\hline 8 & $\begin{array}{l}\text { RMSEA } \\
\text { Sekitar } \\
0\end{array}$ & 0,834 & Tidak baik \\
\hline 9 & CMIN/DF & $<2$ & 73,356 & Tidak baik \\
\hline
\end{tabular}

Karena model awal (gambar 1) belum fit, maka harus dilakukan modifikasi model sesuai dengan anjuran AMOS yang harus dipadukan dengan teori yang ada untuk melakukan hubungan antar variabel. Setelah dilakukan beberapa modifikasi model, ternyata model yang layak utuk diinterpretasi adalah diinterpretasi adalah sebagai berikut:

\section{SWB}

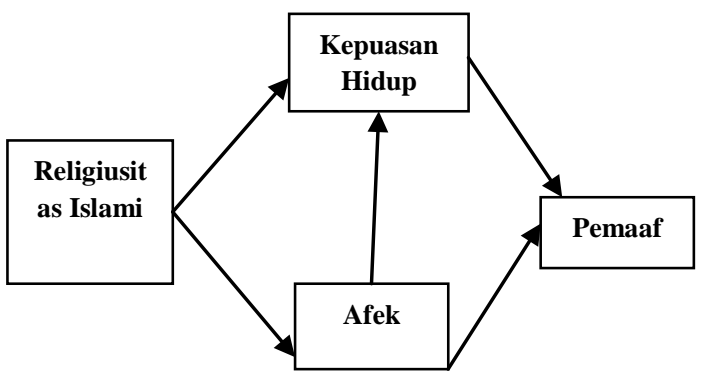

Gambar 2 Modifikasi Model

Uji Goodness of Fit Index (GFI) menunjukkan bahwa hasil analisis pada modifikasi model sebagaimana terlihat dalam gambar 2, secara keseluruhan model ini memenuhi kriteria yang dianggap fit dan layak diinterpretasikan.

Tabel 2. Rangkuman Hasil Pengujian Gambar 2.

\begin{tabular}{|c|c|c|c|c|}
\hline No & $\begin{array}{c}\text { Goodness } \\
\text { of Fit } \\
\text { Index }\end{array}$ & $\begin{array}{c}\text { Cut-off } \\
\text { value }\end{array}$ & Hasil & Keterangan \\
\hline
\end{tabular}




\begin{tabular}{|c|c|c|c|c|}
\hline 1 & $\begin{array}{l}\text { Degree of } \\
\text { freedom }\end{array}$ & $>0,05$ & 1 & Baik \\
\hline 2 & $\begin{array}{l}\text { Probability } \\
\text { level }\end{array}$ & $>0,05$ & 0,164 & Baik \\
\hline 3 & Chi Square & $>0,05$ & 1,935 & Baik \\
\hline 4 & $\begin{array}{l}\text { Goodness } \\
\text { of Fit } \\
\text { Index } \\
\text { (GFI) }\end{array}$ & $>0,900$ & 0,991 & Baik \\
\hline 5 & $\begin{array}{l}\text { Adjusted } \\
\text { GFI } \\
\text { (AGFI) }\end{array}$ & $>0,900$ & 0,909 & Baik \\
\hline 6 & $\begin{array}{l}\text { Normal Fit } \\
\text { Index } \\
\text { (NFI) }\end{array}$ & $>0,900$ & 0,966 & Baik \\
\hline 7 & $\begin{array}{l}\text { Tucker- } \\
\text { Lewis } \\
\text { Index } \\
\text { (TLI) }\end{array}$ & $>0,900$ & 0,9 & Baik \\
\hline 8 & RMSEA & $\begin{array}{l}\text { Sekitar } \\
0\end{array}$ & 0,095 & Baik \\
\hline 9 & CMIN/DF & $<2$ & 1,935 & Baik \\
\hline
\end{tabular}

Besarnya pengaruh atau efek dapat dilihat pada standardized regression weights atau loading factor yang besarnya berkisar antara nilai $0-1$.

Tabel 3. Besarnya Efek Langsung Variabel Bebas dan Variabel Terikat

\begin{tabular}{|l|l|l|c|c|}
\hline $\begin{array}{c}\text { Variabel } \\
\text { Bebas }\end{array}$ & $\begin{array}{c}\text { Variabel } \\
\text { Terikat }\end{array}$ & $\begin{array}{c}\text { Besarnya } \\
\text { Efek }\end{array}$ & C.R. & $\mathbf{P}$ \\
\hline $\begin{array}{l}\text { Religiusitas } \\
\text { Islami }\end{array}$ & Afek & 0,294 & 3,142 & 0,002 \\
\hline $\begin{array}{l}\text { Religiusitas } \\
\text { Islami }\end{array}$ & $\begin{array}{l}\text { Kepuasan } \\
\text { Hidup }\end{array}$ & 0,172 & 1,937 & 0,053 \\
\hline Afek & $\begin{array}{l}\text { Kepuasan } \\
\text { Hidup }\end{array}$ & 0,419 & 4,715 & 0,000 \\
\hline Afek & Pemaafan & 0,204 & 1,978 & 0,048 \\
\hline $\begin{array}{l}\text { Kepuasan } \\
\text { Hidup }\end{array}$ & Pemaafan & 0,232 & 2,251 & 0,024 \\
\hline
\end{tabular}

Tabel 4. Besarnya Efek Tidak Langsung Variabel Bebas dan Terikat

\begin{tabular}{|l|l|l|}
\hline Variabel Bebas & $\begin{array}{l}\text { Variabel } \\
\text { Terikat }\end{array}$ & Besarnya Efek \\
\hline $\begin{array}{l}\text { Religiusitas } \\
\text { Islami }\end{array}$ & $\begin{array}{l}\text { Kepuasan } \\
\text { Hidup }\end{array}$ & 0,124 \\
\hline $\begin{array}{l}\text { Religiusitas } \\
\text { Islami }\end{array}$ & Pemaafan & 0,129 \\
\hline Afek & Pemaafan & 0,097 \\
\hline
\end{tabular}

\section{a. Peran religiusitas islami terhadap pemaafan (forgiveness)}

Setelah dilakukan uji fit model ternyata religiusitas islami dengan pemaafan (forgiveness) tidak ada pengaruh secara rangsung, hal ini terlihat bahwa pada gambar 2 tidak ada anak-anak panah secara langsung antara kedua variabel tersebut. Namun dari out put AMOS dapat diketahui masih ada pengaruh tidak langsung antara kedua variabel tersebut yaitu sebesar 0,129.

Hasil penelitian ini berbeda dengan penelitian Krause dan Ingersoll-Dayton (Nashori, 2011) yang melakukan penelitian terhadap orang-orang lanjut usia berkulit putih maupun hitam Amerika yang berjumlah 129 penganut Katholik dan Protestan yaitu memperoleh hasil bahwa orang-orang lanjut usia yang religius mudah dalam memberikan pemaafan. Begitu pula dengan hasil dari penelitian Nashori (2011) yang menyatakan bahwa orang yang lebih tinggi kualitas dzikirnya akan lebih mudah untuk memaafkan.

Adapun "perbedaan" hasil penelitian ini dengan penelitian sebelumnya ada beberapa kemungkinan. Salah satunya adalah faktor-faktor yang mempengaruhi pemaafan menurut teori ada beberapa faktor, menurut (Nashori, 2008) diantaranya adalah tingkat kelukaan, karakteristik kepribadian, empati, religiusitas, usia, atribusi sosial, dan lain sebagainya. Religiusitas, hanya sebagai salah faktor yang menyebabkan orang mudah untuk memaafkan dan hasil penelitian ini menunjukkan bahwa religiusitas tidak berhubungan secara langsung, tetapi melalui faktor afek dan kepuasan hidup.

Apabila kita perhatikan dalam beberapa teori sebelumnya, pemaafan merupakan sebuah proses (Gani, 2011), maksudnya seseorang yang menjadi korban ketidakadilan kemungkinan kecil secara langsung dapat memaafkan pelaku. Salah satu proses memaafkan yang dikatakan oleh Miller (Gani, 2011) yaitu ada tujuh tahapan dalam proses pemaafan bagi seseorang yang meliputi: memperhatikan peristiwa-pikiran-perasaan-tindakan, menyadari apa yang ingin dimaafkan dan dilepaskannya, membayangkan kehidupan setelah memaafkan, berusaha berbuat baik kepada orang yang menyakiti, meminta 
bantuan kekuatan kepada Tuhan terusmenerus agar dapat menghilangkan rasa sakit hatinya.

Tidak adanya hubungan langsung antara religiusitas islami dengan pemaafan juga kemungkinan disebabkan oleh sifat khas remaja yang menurut Elkin (Santrock, 2004) yaitu sifat egosentrisme yang terdiri dari dua macam yaitu imaginary audience dan personal fable. Kedua sifat egosentrisme remaja ini menginginkan dirinya menjadi pusat perhatian dan menginginkan setiap orang bersikap pada dirinya seperti apa yang dia inginkan. Untuk menghilangkan sifat ini, tentu memerlukan waktu dan proses sebagaimana yang di sebutkan Gani di atas. Sedangkan faktor lain yang kemungkinannya besar mengakibatkan perbedaan hasil penelitian ini dengan hasil-hasil sebelumnya adalah faktor usia. Sebagaimana responden penelitian yang dilakukan Krause dan Ingersoll-Dayton adalah orang lanjut usia, sedangkan pada penelitian ini adalah remaja.

\section{b. Peran religiusitas islami terhadap kepuasan hidup dan afek atau kesejahteraan subyektif (subjective well being)}

Pengaruh religiusitas islami terhadap kepuasan hidup pada penelitian ini terlihat ada hubungan langsung 0,172 (p $=0,053$ ), sedang pengaruh tidak langsung antara religiusitas Islami terhadap kepuasan hidup 0,124 sehingga pengaruh total antara religiusitas Islami terhadap kepuasan hidup adalah 0,296. Adapun pengaruh religiusitas Islami terhadap afek hanya ditunjukkan pengaruh secara langsung sebesar 0,294 (p $=0,002$ ).

Hasil penelitian ini diperkuat oleh beberapa penelitian sebelumnya yang menyatakan bahwa religiusitas dapat meningkatkan kesejahteraan subyektif, misalnya penelitian yang diungkapkan oleh Trede (2006) yang menghasilkan bahwa terdapat korelasi positif antara religiusitas Subjective well being. Hasil penelitian Diponegoro (2004) juga memperoleh hasil yang senada yaitu, pengetahuan ajaran Islam dan nilai-nilai ajaran Islam dapat meningkatkan kesejahteraan subyektif yang di ukur dari kepuasan hidup dan afek.
Temuan pada penelitian ini semakin menunjukkan betapa pentingnya religiusitas dalam kehidupan seseorang. Religiusitas islami menurut Haidt (Diponegoro, 2004) merupakan salah satu agama yang didalam ajarannya diakui mengandung emosi positif. Demikian pula bagi orang yang mempunyai tingkat religiusitas islami yang tinggi tentu akan memperoleh kepuasan hidup yang tinggi pula, sebagaimana dalam aspek religiusitas yang diungkap pada penelitian ini menyangkut pandangan seseorang tentang ajaran agama Islam dan kepribadian islami yang menjadi jalan hidup orang tersebut. Seseorang yang mempunyai keyakinan yang benar terhadap ajaran-ajaran agama Islam dan kemudian dia berusaha menerapkan ajaran agama tersebut dalam kehidupan sehari-hari, maka ia akan mempunyai ketentraman dalam hidupnya. Lebih-lebih agama Islam yang memberi keluasan bagi umatnya (tentu yang memenuhi syarat) dapat memberi tafsiran kreatif ajaran agama yang sesuai dengan perkembangan zaman namun tetap tidak keluar dari petunjuk Nabi akan meningkatkan kepuasan hidupnya. Franklin (Irham, 2011) menyatakan happiness is not more passession of money; is lies in the joy of achievement, in the thrill of creative effort (kebahagiaan tidak terletak pada kepemilikan uang semata; kebahagiaan terletak pada kegembiraan pencapaian, pada getaran upaya kreatif).

Begitu pula dalam skala kepribadian agamis yang diungkap tentang hubungan manusia dengan Tuhan, hubungan sosial dan komitmen dalam ibadah telah banyak diungkap oleh peneliti sebelumnya bahwa aspek-aspek tersebut dapat meningkatkan kebahagiaan subyektif. Misalnya menurut Myers (Diponegoro, 2004) perhatian terhadap agama yaitu dengan meningkatkan religiusitas akan membawa kepada kehidupan yang lebih baik baik pemeluknya. McCullough (Diponegoro, 2004) juga menegaskan bahwa orang yang aktif menjalankan perintah agama akan mendapat kebahagiaan yang lebih dengan prediktor bahwa mereka mempunyai umur yang lebih panjang yang merupakan indikasi subjective well being. 


\section{c. Peran afek terhadap kepuasan hidup}

Berdasarkan out put AMOS dapat diketahui adanya pengaruh langsung dari afek terhadap kepuasan hidup sebesar 0,419. Hasil yang diperoleh penelitian ini mendukung hasil penelitian Diponegoro (2004) yang diperoleh besar pengaruh afek terhadap kepuasan hidup sebesar 0,273. Menurut Frederickson (Diponegoro, 2004) hasil ini mendukung teori Broaden and built theory tentang emosi positif. Menurut teori ini, peningkatan afek positif akan mampu meningkatkan evaluasi kognitif (kepuasan hidup) dan peningkatan emosiemosi positif yang lain.

\section{d. Peran afek dan kepuasan hidup (Kesejahteraan Subyektif) terhadap pemaafan (Forgiveness)}

Setelah dilakukan analisis fit terhadap model ternyata arah hubungan pemaafan dan kesejahteraan subyektif berubah arah. Model menjadi fit ketika arah hubungan menjadi kepuasan hidup dan afek berpengaruh terhadap pemaafan (forgiveness). Dari out put AMOS diperoleh bahwa ada pengaruh langsung afek terhadap pemaafan (forgiveness) sebesar 0,204 $(\mathrm{p}=0,048)$ dan pengaruh tidak langsung sebesar 0,097. Jadi total pengaruh afek terhadap pemaafan (forgiveness) sebesar 0,301. Sedangkan kepuasan hidup hanya berpengaruh langsung terhadap pemaafan (forgiveness) sebesar 0,232 ( $p=0,024)$.

Temuan ini berbeda dengan beberapa temuan sebelumnya yang menyatakan bahwa pemaafan berpengaruh terhadap kesejahteraan subyektif. Penelitian Seligman (2005) dan Toussaint dan Frieman (2008) mendapatkan hasil bahwa pemaafan mempengaruhi subjective well being. Kedua hasil penelitian ini samasama menduga bahwa pemaafan (forgiveness) dapat meningkatkan subjective well being, artinya pemaafan (forgiveness) mempengaruhi kesejahteraan subyektif (subjective well being).

Hubungan antar variabel dalam sebuah penelitian pada saat-saat tertentu sering berubah arah, artinya suatu variabel penelitian yang pada saat tertentu mempengaruhi namun pada saat yang lain dapat dipengaruhi. Misalnya, dalam beberapa penelitian dihasilkan bahwa tingkat kesehatan mempengaruhi afek dan kepuasan hidup seseorang (Urbayatun, 2005). Namun penelitian Lyubomirsky dari University of California yang dipublikasikan oleh American Psychological Association (APA) (Wirawan, 2010), memperoleh hasil bahwa orang-orang yang berbahagia akan lebih berhasil di sepanjang rentang hidupnya dibandingkan dengan orang yang kurang berbahagia. Di samping itu, orang yang berbahagia akan lebih mudah mencapai situasi kondisi kehidupan yang lebih menyenangkan. Hal ini dimungkinkan terjadi karena orang yang berbahagia kerapkali mengalami suasana hati yang positif dan suasana hati positif ini menggugah mereka untuk bekerja dengan lebih aktif untuk mencapai tujuan yang baru dan membangun sumber daya yang baru. Ketika orang merasa berbahagia, mereka cenderung merasa percaya diri, optimis, dan energik, dan orang lain berpandangan bahwa mereka adalah orangorang yang lebih disukai dan lebih mudah bergaul ("Review of Research Challenges Assumption that Success Makes People Happy,” 2005).

Hasil penelitian Lyubomirsky diatas jika di hubungkan dengan hasil penelitian ini sangat selaras, dimana orang yang mempunyai kesejahteraan subyektif maka akan mudah memaafkan. Menurut Gani (2011) orang yang dapat merubah afek negatif menjadi afek positif maka akan lebih mudah untuk memaafkan. Demikian pula dengan orang yang mempunyai kepuasan hidup, ia akan lebih asertif sehingga lebih mudah untuk memaafkan. Wirawan (2010) mengutip lagi Review Of Research Challenges Assumption That Success Makes People Happy yang menyatakan bahwa orang yang mempunyai kesejahteraan subyektif akan menjadi orang-orang yang lebih disukai dan lebih mudah bergaul karena mereka dapat menerima orang lain apa adanya dan dapat memaafkan segala kekurangannya bahkan dapat mengambil hikmah dari kekurangan orang lain. Lebih jauh lagi, penelitian ini juga mendapatkan hasil bahwa kesejahteraan subyektif seseorang dapat diasosiasikan dengan persepsi positif diri sendiri dan orang lain, sosiabilitas, kreativitas, perilaku prososial, yang 
menjadi prasyarat orang mudah memaafkan.

$$
\text { Menurut Muhadjir (2011), }
$$

perubahan arah pengaruh suatu variabel terhadap variabel tertentu dapat disebabkan oleh beberapa hal, diantaranya adalah: 1) aspek-aspek variabel yang diteliti tidak valid, 2) variabel terlalu besar sehingga perlu dilakukan pengembangan variabelitas, dan 3) ada perbedaan subyek yang terlalu mencolok sehingga harus dilakukan pemecahan subyek. Masih menurut Muhadjir (2011) hal yang sangat mungkin pada penelitian ini adalah perbedaan subyek sebagaimana yang telah peneliti sampaikan pada pembahasan sebelumnya, yaitu pada penelitian ini peneliti tidak melakukan penggolongan usia responden.

\section{e. Peran Antar Variabel Pada Model Hasil Penelitian}

Dari pembahasan peran antar variabel dengan variabel yang lain pada bagian-bagian di atas, maka dapat disimpulkan peran antar variabel pada model hasil penelitian secara terpadu. Seseorang yang mempunyai religiusitas tinggi akan mempengaruhi tingkat kepuasan hidup orang tersebut dan juga akan mempengaruhi afeknya. Sementara afek yang dibentuk oleh religiusitas seseorang akan mempengaruhi secara langsung pemaafan pada diri orang itu. Begitu pula afek yang dibentuk oleh religiusitas seseorang secara tidak langsung yaitu melalui peningkatan kepuasan hidupnya, akhirnya akan mempengaruhi pemaafan pada diri orang itu pula. Sementara itu, religiusitas seseorang akan mempengaruhi secara langsung terhadap kepuasan hidup orang tersebut, dimana akhirnya kepuasan hidup tersebut akan mempengaruhi pemaafan pada dirinya.

Oleh karena religiusitas tidak berpengaruh langsung terhadap pemaafan, namun mempengaruhi secara langsung maupun tidak langsung terhadap afek dan kepuasan hidup yang setelah itu baru akan mempengaruhi terhadap pemaafan, maka untuk meningkatkan pemaafan pada diri seorang remaja, religiusitas islami bukan satu-satunya permasalahan yang perlu mendapat perhatian besar. Afek atau perasaan mempunyai peran yang tidak kalah besarnya untuk diperhatikan jika dibandingkan dengan religiusitas islami.

Hasil penelitian sebagaimana diuraikan di atas tidak terlepas dari model yang diterima dari penelitian ini. Yaitu, dalam penelitian ini religiusitas islami berperan sebagai satu-satunya variabel eksogenus sehingga hanya mempengaruhi terhadap variabel lain. Sementara variabel afek dan kepuasan hidup berperan ganda yaitu sebagai variabel endogenus bagi variabel dan religiusitas islami dan berperan sebagai variabel eksogenus bagi variabel pemaafan. Sedangkan variabel pemaafan hanya berperan sebagai variabel endogenus yang hanya dipengaruhi oleh variabel-variabel lain.

\section{KESIMPULAN}

Berdasarkan penelitian yang telah dilakukan, maka dapat disimpulkan Hasil penelitian menunjukkan:

a. Tidak ada pengaruh langsung religiusitas terhadap pemaafan. Ada pengaruh tidak langsung religiusitas terhadap pemaafan sebesar 0,129.

b. Ada pengaruh langsung religiusitas terhadap kepuasan hidup sebesar 0,172 $(\mathrm{p}=0,053) \quad$ Ada pengaruh tidak langsung sebesar 0,124, total pengaruh 0,296.

c. Ada pengaruh langsung religiusitas terhadap afek sebesar $0,294(p=0,002)$. Ada pengaruh langsung afek terhadap kepuasan hidup sebesar 0,419.

d. Ada pengaruh langsung afek terhadap pemaafan sebesar $0,204 \quad(p=0,048)$ dan pengaruh tidak langsung sebesar 0,301 sehingga total pengaruh sebesar 0,301 ;

e. Ada pengaruh langsung kepuasan hidup terhadap pemaafan sebesar 0,232 $(\mathrm{p}=0,024)$.

\section{REFERENSI}

Abraido-Lanza, A.F., Vasquez, E., \& Echeverria, S.E. 2004. En las manos dios (in God's hands): Religious and other forms of coping among latinos with arthritis. Journal of Consulting and Clinical Psychology, 72, 91-102.

Alsa, A. (2010). Pendekatan Kuantitatif \& Kualitatif serta Kombinasinya dalam Penelitian Psikologi. Yogyakarta: Pustaka Pelajar 
Argyle, M. 2001. The Psychology of Happiness. New York: Taylor \& Francis.

Azwar,S. (1997). Penyusunan Skala Psikologi. Yogyakarta: Pustaka Pelajar.

Benson, H. 2000. Dasar-dasar Respons Relaksasi. (Terjemahan). Bandung: Kaifa

Boglarsky,C.A \& Kwantes,CT. (2005). Who is Happy and Why? Subjective Well Being and Associative Thinking Styles of US and Canadian Students. Presented at $17^{\text {th }}$ annual Convention of The American Psychological Society.

Boven, L.V., \& Gilovich, T. 2003. To do or to have? That is the question. Journal Personality and Social Psychology, 85, 1193-1202.

Bradshaw,J; Keung,A; Rees, G \& Goswami,H. (2009). Explaining Variations in The Subjective Well Being of Children: Macro \& Micro Approaches. Paper for Social Policy association Conference, University of Edinburgh.

Brickman, P. Coates, D., \& Janoff-Bulman, R.J. 1978. Lottery winners and accident victims: Is happiness relative? Journal of Personality and Social Psychology , 36, 917-927.

Carr, A. (2004). Positive Psychology. The Science of Happiness and Human Strengths. London: Routledge

Crocker, J., Quinn, D.M., Karpinski, A., \& Chase, S.K. 2003. When Grades determine self-worth: Consequences of contingent welf-worth for male and female engineering and psychology majors. Journal of Personality and Social Psychology, 85, 507-516.

Csikszentmihalyi, M. 1999. If we are so rich, why aren't we happy? American Psychologist, 55, 821-827

Cummins,R.A. (2000). Objective and subjective quality of life: an
Interactive model. Social Indicator Research. 52, 52-57.

Dalton,W.T; Kitzmann,K.M; Burghen,G.A; Mallare,J.T; Stender,S.S. (2009). Family functioning and children's response to primary care treatment for overweight: a preliminary study. Journal of Pediatric Nursing. $X x, x x x-$ $x x x$

Dister, N.S. (1993). Pengalaman dan Motivasi Beragama. Yogyakarta: Kanisius

Darby, B.W. and Schlenker, B. R. 1982. Children Reactions to Apologies. Journal of Personality and Social Psychology, 43 (4), 742-753.

Droll, D. M. 1984. Forgiveness: Theory and Research. Dissertation Abstracts International-B, 45, 2732.

Diener, E. Horwtiz, J. \& Emmons, R.A. 1985. Happiness of the very wealthy. Social Indicator Research , 16, 263-274.

Diener, E., Suh, E.M., Lucas, R.E., \& Smith, H.L. 1999. Subjective Well-Being: Three Decades of Progress. Psychological bulletin, 125, 276-302.

Diener, E., Gohm, L. C., Suh, E., \& Oishi, S. 2000. Similarity of the relationship marital status happiness across cultures. Journal of Cross Cultural Psychology, 31, 419-436.

Diener, E., Lucas, R.E., Oishi, S., and Suh, E.M. 2001. Looking up and looking down: Weighting good and bad information in life satisfaction judgments. Manuscript under review.

Diener, E. \& Scollon, C. 2003. Happiness is desirable, but not the summun bonum. Paper delivered at the University of Minnesota interdisciplinary Workshop on Well-Being, October 23 - 25, 2003, Minneapolis.

Diener,E. (2008). Assessing subjective well being: progress and opportunities. Social Indicator Research , 31(2), 103. 
Diponegoro, A.M. (2004). Peran Nilai Ajaran Islam Terhadap Kesejahteraan Subjektif Remaja Islam. Disertasi. Yogyakarta: Universitas Gadjah Mada.

Diponegoro, A.M. (2010). Psikologi Konseling Islami dan Psikologi Positif. Yogyakarta: UAD Press

Diponegoro, M., \& Thalib, S.B. 2001. MetaAnalisis tentang Perilaku Koping Preventif dan Stress. Psikologika, 12, 51-62.

Diponegoro, A.M. 2012. Konseling dalam Islam. PSIKOPEDAGOGIA Jurnal Bimbingan dan Konseling, 1(2): 4047.

Durr, L.I. (2008). Optimal challenge: the Impact of adventure experiences on subjective well being. Journal of Experiental Education. 31 (3).

Enright, R.D. 2002. Forgiveness Is a Choice: AG Step-by-Step Process for Resolving Anger and Restoring Hope. Washington DC: American Psychological Association.

Friedman, P.H. dan Toussaint, L. (2005). The Relationship Between Forgiveness, Gratitude, Distress, And Well-Being: An integrative review of the literature. The International Journal of Healing and Caring, 6/2, 1-10 May.

Gallagher,E.N; Brodrick, D.A.V. (2008). Social support and emotional intelligence as predictors of subjective well-being. Personality and Individual Differences 44,1551-1561

Gani, A.H. (2011). Forgiveness Therapi. Maafkanlah, Niscaya Dadamu Lapang. Yogyakarta: Kanisius

Ghozali, I. (2009). Aplikasi Analisis Multivarite dengan Program SPSS. Semarang Badan Penerbit Universitas Diponegoro.
Hawari, D. (1996). Islam dan Kesehatan Mental. Yogyakarta: PT Dana Bhakti Wakaf

Headey,B \& Wooden,M. (2004). The effects of wealth and income on subjective well being and ill being, Melbourne Institute Working Paper No. 3/04, ISSN 1447-5863.

Henson, K.T \& Ellen,B.F. (1999). Educational Psychology for effective Teaching. Wodsworth Publishing Company.

Heshmati. A; Bajalan, C.S.J \& Tausch, A. (2007). Measurement and Analysis of Child Well Being in Middle and High Income Countries. IZA Discussion Paper, No. 3203.

Hidayat, K. (2010). Psikologi Agama. Jakarta: Hikmah

Huppert,F.A; Baylis,N; Keverne,B. (2005). Huppert,et.al (ed). The Science of Well Being. Oxford University Press.

Jalaluddin \& Ramayulis (1993) Pengantar Ilmu Jiwa Agama. Jakarta: Kalam Mulia.

Joronen,K. (2005). Adolescence's Subjective Well Being in Their Social Contexts. Finland: University of Tampere; Academic Dissertation.

Kashdan, T.B. (2003). The assessment of subjective well-being (issues raised by the Oxford Happiness Questionnaire). Personality and Individual Differences, 36, 1225-1232.

Krauss, S.E. (2005). Development Of The Muslim Religiosity-Personality Inventory For Measuring The Religiosity of Malaysian Muslim Youth. Disertasi. www. Calameo.com

Krauss, S.E. et.all (2005), The Muslim Religiosity-Personality Measurement Inventory (MRPI)'s Religiosity Measurement Model: Towards Filling the Gaps in Religiosity Research on Muslims Pertanika J. Soc. Sci. \& Hum. 13 (2): 131-145. 
Krueger,A.B \& Schade,D.A. (2007). The reliability of Subjective well Being measures. National Institute on Aging, and Princeton University's Woodrow Wilson School

Linley,P.A; Maltby,J; Wood,A.M; Osborne,G; Hurling,R. (2009). Measuring happiness: the higher order factor structure of subjective well being measures. Personality and Individual Differences, 47, 878-884.

Lopez, S.J. \& Snyde C.R. (2004) Positive Psichological Assesment. A Handbook of Models and Measures. Washington: American Psychological Association.

McCullough, M.E., David B., Larson, D.B., William T., Hoyt, W.T., Koenig, H.G., \& Thoresen. C. E. 2000. Religious Involvement and Mortality: A MetaAnalytic Review, Health Psychology, 19, 211-222.

Muhadjir, N. (2011). Ed. VI Pengembangan, Metodologi Penelitian. Yogyakarta: Rake Sarasin.

Myers, D. G.1993. The Pursuit of H appiness. New York: Aquarian

Myers, D.G. 2000. Funds, friends, and faith of happy people. American Psychologist, 55, 56-67

Nashori, H. F. 2005. Hubungan Kualitas Dzikir dan Pemaafan pada Mahasiswa. Jurnal Psikologi (Undip), Vol. IX, No. 1, 27-35.

Nashori, H.F. 2009. Kepemimpinan dan Pemaafan. Dalam Fuad Nashori, Sus Budiharto, \& Yulianti Dwi Astuti (eds.) Psikologi Kepemimpinan. Yogyakarta: Penerbit Fahima.

Nashori, H.F., Setiono, K. \& Agustina, I. 2010. Forgiveness in Javenese and Batakese Ethnicities. Paper presented on The First International Conference of Indigenous and Cultural Psychology, Yogyakarta, July 24-27.
Nashori, H.F., \& Setiono, K. 2010. Pemaafan pada Etnis Jawa: Sebuah Kajian Teoritik. Jurnal Psikoislamika, 8 (1), 89-9105.

Nashori, H.F., \& Mucharam, R.D. 2002. Mengembangkan Kreatifitas dalam Perspektif Psikologi Islami. Yogyakarta: Menara Kudus Jogja.

Nashori, H.F, Iskandar, T.Z., Setiono, K., \& Siswadi, A.G.P. 2011. Tema-tema Pemaafan pada Mahasiswa Muslim Yogyakarta. Laporan Penelitian. Yogyakarta: Fakultas Psikologi dan Ilmu Sosial Budaya UII.

Nesse, R.M. (2005). Natural Selection and The Elusiveness of Happiness, available at Hippert, et.al (ed). The Science of Well Being. Oxford University Press.

Nottingham, E.K. (1990). Agama dan Masyarakat, Suatu Pengantar Sosiologi Agama. Jakarta: Rajawali Press

Oman, D. \& Reed, D. 1998. Religion and mortality among the communitydwelling elderly. American Journal of Public Health, 88, 14691475.

Owusu-Ansah, F.E. (2008). Control perception and control appraisal: relation to measures of subjective well being. Ghana Medical Journal, 42 (2), 61-67.

Qordhawi, Y. (1997). Tugas Pemuda Islam. Titian Ilahi Press: Yogyakarta

Rakhmat, J. (2010). Tafsir Kebahagiaan. Mensikapi Musibah yang Kita Alami. Jakarta: Serambi

Razak, N. (1985). Dienul Islam. Bandung: PT. Al-Ma'arif

Ryan. M.R., \& Deci, E. L. (2001). On happiness and human potentials: a review of research on hedonic and eudaimonic well-being. Annual Review of Psychology, 52, 141-157. 
Ryff, C. D. \& Keyes, C. L. M. (1995). The structure of psychological well-being revisited. Journal of Personal and Social Psychology, 69, 719-727.

Safren, S,A; Radomsky,A.S; Otto,M.W \& Salomon,E. (2002). Predictors of psychological well being in a diverse sample of HIV-positive patients receiving highly active antiretrovial therapy. Psychosomatic, 43 ( 6), 478.

Salovey, P., Rothman, A.J., Dersweller, J.B., \& Steward, W. T. 2000. Emotional States and Physical health. American Psychologist, 55, 110-121

Santoso, S. (2002). Buku Latihan SPSS Statistik Multivariat. Jakarta: Alex Media Komputindo

Santoso, S. (2007). Structural Equation Modelling. Konsep dan Aplikasi ddengan AMOS. Jakarta: Alex Media Komputindo

Schimmack, U., Radhakrishnan, P., Oishi, S., Dzokoto, V., \& Ahadi, S. 2002. Culture, Personality, and Subjective Well-Being: Integrating Process Models of Life-Satisfaction. Journal Personality and Social Psychology, 82, 582-593.

Seligman, M.E.P. (1999). Transcript of $a$ speech given by Dr. Martin E.P. Seligman at the Lincoln Summit in September of 1999.

Seligman, M.E.P. (2005). Authentic Happiness. Menciptakan Kebahagiaan dengan Psikologi Positif. Terjemahan: Nukman, E.Y. Bandung: Mizan

Setyawan, I. (2007) Membangun Pemaafan pada Anak Korban Perceraian. Makalah. Bandung: Konferensi Nasional I IPK-HIMPSI

Sihombing, H.M.L. (2011) Hubungan antar Konflik Peran Ganda dengan Life Satisfaction pada Wanita Bekerja, repository.usu.ac.id/bitstream/123456 789/23986
Snyder, C.R., \& Lopez, S. J. 2007. Positive Psychology: The Scientific and Practical Explorations of Human Strengths. California: Sage Publications, Inc.

Suh, E., Diener, E., Oishi, S., \& Triandis, H. C. 1998. The shifting basis of life satisfaction judgments across cultures: Emotions versus norms. Journal of Personality and Social Psychology, 74, 482-493.

Trede, T.A. (2006). An investigation of the relationship between religiosity and subjective well-being in older adults: The mediating role of optimism. Theses and Dissertations, University of South Florida.

Urbayatun, S. (2005) Hubungan antara Pemenuhan Kebutuhan Afek dengan Kesehatan Lansia. Tesis. Yogyakarta: Universitas Gadjah Mada.

Wardhati, L.T. \& Faturochman. 2006. Psikologi Pemaafan. Jurnal Psikologi (UGM), 14 (1), 57-67.

White, S. C. (2008). 'But what is wellbeing? A framework for analysis in social and development policy and practice'. Paper for Regeneration and Wellbeing: Research into Practice. Available at http://www.bath.ac.uk/cds/but_what_i s\%20_wellbeing.pdf

Wibisono, S. (2010). Subjective Well Being Among Adolescence of Woman Migran Workers Based On Their Self Acceptance, Family Functioning, And Positive Coping, Tesis, Yogyakarta: Universitas Gadjah Mada.

Wiyata, A.L. (2006). Carok, Konflik Kekerasan dan Harga Diri Orang Madura. Yogyakarta: LKiS

Winkelman,R. (2004). Subjective well Being and The Family: Result from an Ordered Probit Model with Multiple Random Effects. IZA Discussion Paper Series, No.1016. 
Wirawan, H.E. (2010) Kebahagiaan Menurut Dewasa Muda Indonesia, Laporan penelitian.

www.psikologi.tarumanagara.ac.id/.../ 15-kebahagiaan-menurut-dewa.

Yamamoto,J. (2006). Subjective Well being from a Developing Country Perscpective: An Alternative Multilevel Approach. 